ORIGINAL ARTICLE

\title{
Epidemiology of injuries and illnesses in America's Cup yacht racing
}

\author{
V J Neville, J Molloy, J H M Brooks, D B Speedy, G Atkinson
}

Br J Sports Med 2006;40:304-312. doi: 10.1136/bjsm.2005.021477

See end of article for authors' affiliations

Correspondence to:

Vernon Neville, School of

Sport and Exercise

Science, Loughborough

University, Loughborough,

UK; vneville@hotmail.com

Accepted 1 December 2005 and severity of injuries and illnesses incurred by a professional Objectives: To determine the incidence and severity of injuries and illnesses incurred by a professional
America's Cup yacht racing crew during the preparation for and participation in the challenge for the 2003 America's Cup.

Methods: A prospective study design was used over 74 weeks of sailing and training. All injuries and illnesses sustained by the 35 professional male crew members requiring medical treatment were recorded, including the diagnosis, nature, location, and mechanism of injury. The volume of sailing and training were recorded, and the severity of incidents were determined by the number of days absent from both sailing and training.

Results: In total, 220 injuries and 119 illnesses were recorded, with an overall incidence of 8.8 incidents/ 1000 sailing and training hours (injuries, 5.7; illnesses, 3.1). The upper limb was the most commonly injured body segment (40\%), followed by the spine and neck (30\%). The most common injuries were joint/ ligament sprains $(27 \%)$ and tendinopathies (20\%). The incidence of injury was significantly higher in training (8.6) than sailing (2.2). The most common activity or mechanism of injury was non-specific overuse (24\%), followed by impact with boat hardware (15\%) and weight training (13\%). "Grinders" had the highest overall injury incidence (7.7), and "bowmen" had the highest incidence of sailing injuries (3.2). Most of the illnesses were upper respiratory tract infections (40\%).

Conclusions: The data from this study suggest that America's Cup crew members are at a similar risk of injury to athletes in other non-collision team sports. Prudent allocation of preventive and therapeutic resources, such as comprehensive health and medical care, well designed conditioning and nutritional programmes, and appropriate management of recovery should be adopted by America's Cup teams in order to reduce the risk of injury and illness.
$\mathrm{T}$ he America's Cup is regarded as the pinnacle of yacht racing and is held every three to four years between challenging yacht clubs representing their respective countries, with some teams boasting budgets of over $£ 100 \mathrm{~m}$. The event is a series of "match races" between two boats at a time, with each race lasting two to three hours. Teams compete in up to 50 races during the event, which takes place over 22 weeks. All manoeuvres on-board are performed manually without assistance from stored energy; consequently high physical and psychological demands are placed on the 16 person crew. The intensity and demands depend on the position or role of the athlete, ${ }^{1-7}$ the weather conditions, the race tactics, and the competitiveness of the opposition. Preparation for the event involves two to four years of training; consequently the vast majority of time is spent in training rather than in competition. The training comprises land based activities, such as strength and conditioning, and on-water sailing. With the inclusion of other daily activities, such as debriefs and boat maintenance, an average working day is 9-14 hours.

A major risk for athletes during periods of high training volumes is that of injury or illness. ${ }^{8-10}$ Mitigation of this risk by effective preventive and therapeutic interventions requires the determination of injury and illness incidence, severity, and risk. ${ }^{11}$ Unfortunately previous descriptive reports of injuries sustained by America's Cup teams have lacked clarity in their definition of injury and method of data collection, and have not included incidence and severity. ${ }^{14712}$ Furthermore, other off-shore ocean yacht races have very different race formats and crew demands from that of the America's Cup, limiting the applicability of the injury epidemiology published. ${ }^{13-17}$
The aims of this study were to document the injuries and illnesses sustained by a professional America's Cup crew for a period of two years before and during the 2003 America's Cup challenge, and to provide an insight into the incidence, severity, and mechanisms of America's Cup injuries and illnesses.

\section{METHOD}

A prospective study design was used to collect the injury and training data of a professional America's Cup yacht racing crew during the preparation for and participation in the Challenge for the 2003 America's Cup. All crew members signed a consent form allowing their medical and training details to be collected and used in the study. The study complied with the ethical principles of the Loughborough University ethical advisory committee.

\section{Participants}

There were 35 male crew members, representing eight different nationalities. The experience and success of the crew included a total of 20 Olympic campaigns, seven Olympic medals, 70 World Championship titles, nine "Round the World" races, and 90 previous America's Cup campaigns. At the start of the study the mean (SD) age, body mass, and body fat percentage of the crew were 33 (5) years, $90(9) \mathrm{kg}$, and $12.5(5.4) \%$ respectively. ${ }^{18}$

Abbreviations: PINE, posterior interosseous nerve entrapment; URTI, upper respiratory tract infection 


\section{AMERICA'S CUP INJURY REPORT FORM}

\section{ATHLETE IDENTIFICATION:}

Name of Athlete: Athlete code:

Sailing position: [ ] bowman, [ ] mid-bowman, [ ] mastman, [ ] pitman, [ ] pit-assist, [ ] grinder-p, [ ] grinder-s, [ ] trimmer-p, [ ] trimmer-s, [ ] grinder-main, [ ] trimmer-main, [ ] traveler, [ ] helmsman, [ ] strategist, ] tactician, [ ] navigator, [ ] grinder-aft

\section{INJURY DESCRIPTIONS:}

Date of injury: /

Venue: [ ] boat, [ ] chase-boat, [ ] base, [ ] gym, [ ] field, [ ] count, [ ] pool, [ ] beach

Conditions: [ ] $>30^{\circ} \mathrm{C}$, [ ] $20-29^{\circ} \mathrm{C},\left[\right.$ ] $<20^{\circ} \mathrm{C}$, [ ] raining/wet, [ ]

Activity: [ ] sailing-testing, [ ] sailing-training, [ ] sailing-racing, [ ] land based training, [ ] combination overuse, [ ] boat maintenance, [ ] unknown

Mechanism of injury: [ ] boat hardware-impact, [ ] pulling/lifting sails, [ ] grinding, [ ] sustained posture, [ ] sanding boat, [ ] weight training, [ ] interval training, [ ] conditioning games, [ ] circuit training, [ ] fitness testing, [ ] non specific overuse

Specific Activity:

\section{INJURY DETAILS:}

Anatomical location: [ ] head, [ ] face, [ ] cervical spine, [ ] cervicothoracic jxn, [ ] thoracic spine, [ ] thoracolumbar jxn, [ ] lumbar spine, [ ] shoulder, [ ] chest, [ ] upper arm, [ ] elbow, [ ] forearm, [ ] wrist,

[ ] hand/fingers, [ ] abdominals, [ ] hip/pelvis, [ ] upper leg, [ ] knee, [ ]lower leg, [ ] ankle, [ ] foot

Nature of injury: [ ] joint/ligament sprain, [ ] tendinopathy, [ ] muscle strain/tear, [ ] hernia, [ ] joint dysfunction, [ ] spondylosis, [ ] contusion/haematoma, [ ] laceration, [ ] abrasion, [ ] neuropathy, [ ] myofacial pain, [ ] bursitis, [ ] fracture, [ ] dislocation

Type of injury: [ ] acute, [ ] overuse

Status of injury: [ ] new, [ ] recurrent, [ ] pre-existing/old injury

Diagnosis of injury:

\section{ILLNESS:}

Diagnosis of illness:

Recommendations/Referrals:

\section{TREATMENT:}

First referral: [ ] doctor, [ ] physiotherapist, [ ] trainer, [ ] no-one, [ ] A\&E

Initial treatment: [ ] ice, [ ] strapping, [ ] suture, [ ] X-ray, [ ] MRI

Medication: [ ]NSAIDS, [ ] paracetamol, [ ] antibiotics

Proposed therapy: [ ] rest, [ ] no sailing, [ ] modified training, [ ] physiotherapy, [ ] massage, [ ] chiropractor

Treatments: [1], [2], [3], [4], [5], [6], [7], [8], [9], [10], [1 1], [12], [13], [14], [15], [16], [17], [18], [19]

$[20],[21],[22],[23],[24],[25],[26],[27],[28],[29],[30],[31],[32],[33],[34],[35],[36]$

Date of return to sailing: I 1 Date of return to training: / /

Figure 1 Injury report form.

\section{Study periods}

The study period covered 74 weeks of sailing and training. This was divided into four periods, each with a different sailing objective and separated by a four to six week transition phase. The mode of sailing in period A ( 15 weeks) was predominantly boat testing, period B ( 25 weeks) was crew training and race training, and period C ( 12 weeks) was crew training and boat testing. Period D ( 22 weeks) was the competition phase and included the first 13 weeks of the 2003 America's Cup challenger series (the Louis Vuitton Cup).

\section{Assessment of injury and illness}

A reportable injury was defined as "any injury occurring as a result of scheduled sailing or training causing pain, disability or tissue damage, resulting in at least one treatment from the 
Table 1 An overview of the sailing and training demands and the incidence of injury and illness during the four study periods

\begin{tabular}{|c|c|c|c|c|c|c|c|}
\hline \multirow[b]{2}{*}{ Period } & \multirow[b]{2}{*}{$\begin{array}{l}\text { Number } \\
\text { of weeks }\end{array}$} & \multirow[b]{2}{*}{$\begin{array}{l}\text { Sailing } \\
\text { intensity }\end{array}$} & \multirow[b]{2}{*}{$\begin{array}{l}\text { Training } \\
\text { intensity }\end{array}$} & \multirow[b]{2}{*}{$\begin{array}{l}\text { Average } \\
\text { exposure }\end{array}$} & \multicolumn{3}{|c|}{ Number (incidence/1000 h) } \\
\hline & & & & & Injury & Illness & $\begin{array}{l}\text { All } \\
\text { incidents }\end{array}$ \\
\hline$A$ & 15 & Low & Low & 23 & $52(4.8)$ & $32(3.0)$ & $84(7.8)$ \\
\hline B & 25 & High & Moderate & 18 & $89(6.4)$ & $43(3.1)$ & $132(9.5)$ \\
\hline C & 12 & Moderate & High & 13 & $40(7.3)$ & $8(1.5)$ & $48(8.8)$ \\
\hline D & 22 & Moderate & Low & 12 & $39(4.7)$ & $36(4.3)$ & $75(9.0)$ \\
\hline All & 74 & - & - & 17 & $220(5.7)$ & $119(3.1)$ & $339(8.8)$ \\
\hline
\end{tabular}

Sailing intensity was determined by the main mode of sailing during each period: boat testing = low; crew training and boat testing = moderate; race training and/or crew training = high. Training intensity was categorised according to a three point subjective Likert scale, which was reported by each athlete after each training session. Average exposure is sailing + training (hours/week/athlete).

crew's medical staff." A reportable illness was defined as "any non-injury related medical condition requiring medication or treatment". Consultations, medical advice, soft tissue massage, or non-specific treatments that did not meet this criterion were not included.

A recurrent injury was defined as the recurrence of an injury previously requiring medical intervention during the study period. A pre-existing injury was defined as an injury or degenerative condition that was diagnosed by the crew's medical staff as being present before the start of the study and/or being contracted with the team.

Overuse injuries were defined as those resulting from a gradual development of symptoms, whereas acute injuries were defined as those resulting from a specific, single traumatic event.

Two measures of injury and illness severity were used:

- absence from sailing: "the number of days absent from sailing as a result of injury or illness"

- absence from full training: "the number of days absent from full training as a result of injury or illness"

\section{Data collection}

All injuries and illnesses were diagnosed and reported by the crew's medical staff, which included a sports physician, a general practitioner, a physiotherapist, and a chiropractor, on a standard injury report form (fig 1). The diagnoses of all injuries were confirmed by the team's sports physician. All land based training sessions, including the duration and type of training performed and the crew attendance, were reported by the crew's exercise physiologist. All sailing sessions, which included the type of sailing performed, the number of crew, and the number of hours sailed, were reported by the crew manager.

\section{Data analysis}

Exposure time was defined as "the total number of hours that each athlete was engaged in scheduled training and sailing". Incidence was calculated as the number of injuries or illnesses/1000 athlete sailing or athlete training hours. The $\chi^{2}$ goodness of fit test was used to determine the difference between the observed and expected incidence of injury or illness across groups and time periods.

\section{RESULTS}

Table 1 shows an overview of the sailing and land based training demands placed on the crew as well as the number of incidents (injury and illness) during the four study periods. There was a decline in the volume of training and sailing exposure performed between the first period of boat testing (period A) and the final competition phase (period D).

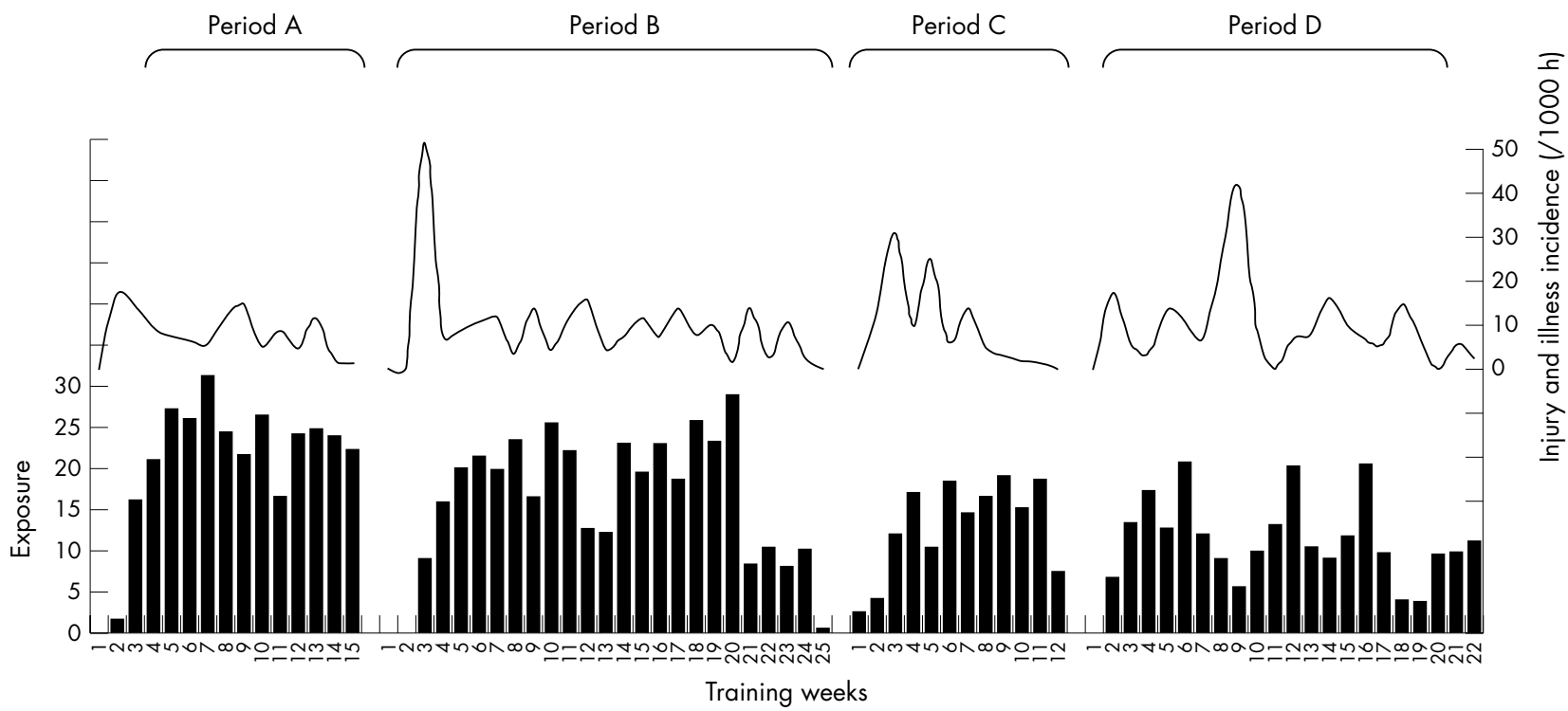

Figure 2 Average sailing and training exposure per athlete (bar graph) and the incidence of injury and illness (line graph) for each week during four training periods in preparation for the America's Cup. Exposure is exposure to sailing and training (hours/athlete/week). 


\begin{tabular}{|c|c|c|c|c|}
\hline \multirow[b]{2}{*}{$\begin{array}{l}\text { Activity when injured } \\
\text { or mechanism of injury }\end{array}$} & \multicolumn{2}{|c|}{ Injury incidence } & \multicolumn{2}{|l|}{ Injury severity } \\
\hline & $\begin{array}{l}\text { Number } \\
(\%)\end{array}$ & $\begin{array}{l}\text { Number } \\
\text { per } \\
\text { athlete }\end{array}$ & $\begin{array}{l}\text { Total days } \\
\text { absent from } \\
\text { sailing } \\
\text { (average/injury) }\end{array}$ & $\begin{array}{l}\text { Total days } \\
\text { absent from full } \\
\text { training } \\
\text { (average/injury) }\end{array}$ \\
\hline Training activity & 74 (34) & 2.1 & $267(3.6)$ & $804(10.9)$ \\
\hline Weight training & $29(13)$ & 0.8 & $93(3.2)$ & $201(6.9)$ \\
\hline Interval running & $26(12)$ & 0.7 & $48(1.8)$ & $339(13.0)$ \\
\hline Conditioning games & $13(6)$ & 0.4 & $42(3.2)$ & $118(9.1)$ \\
\hline Fitness testing & $4(2)$ & 0.1 & $76(19.0) \dagger$ & $111(27.8)$ \\
\hline Arm ergometer training & $2(1)$ & 0.1 & $8(4.0)$ & $35(17.5)$ \\
\hline Sailing & $66(30)$ & 1.9 & $106(1.6)$ & $441(6.7)$ \\
\hline Impact with boat hardware & $34(15)$ & 1.0 & $58(1.7)$ & $226(6.6)$ \\
\hline Specific overuse & $11(5)$ & 0.3 & $8(0.7)$ & $88(8.0)$ \\
\hline Pulling/lifting sails & $10(5)$ & 0.3 & $3(0.3)$ & $30(3.0)$ \\
\hline Sustained posture & $7(3)$ & 0.2 & $0(0.0)$ & $56(8.0)$ \\
\hline Grinding & $4(2)$ & 0.1 & $37(9.3)$ & $41(10.2)$ \\
\hline Non-specific overuse* & $52(24)$ & 1.5 & $393(7.6)$ & $761(14.6)$ \\
\hline Other & $28(13)$ & 0.8 & $178(6.4)$ & 346 (12.4) \\
\hline All & $220(100)$ & 6.3 & $944(4.3)$ & $2352(10.7)$ \\
\hline
\end{tabular}

In total 29900 hours of sailing and 8583 hours of training were reported, during which 339 incidents (220 injuries and 119 illnesses) were recorded. A larger proportion of the injuries $(70 \%)$ and illnesses $(67 \%)$ caused modification of training rather than absence from sailing $(23 \%$ and $60 \%$ respectively). The prevalence of injuries and illnesses causing absence from sailing (expressed as the percentage of athletes absent) was $6.2 \%$, and that causing absence from full training was $15.4 \%$. Figure 2 shows the total sailing and training exposure and the incidence of incidents (injuries and illnesses) for each week of the study.

\section{Injuries}

Table 2 shows the frequency and severity of injuries sustained during different activities. The most common injurious training activity was weight training (13\% of all injuries); a large proportion of these injuries were to the shoulder (48\%). The incidence of acute injuries $(67 \%)$ was significantly higher than the incidence of overuse injuries $(33 \%)\left(p<0.0005 ; \chi^{2}\right.$ $=26.3 ; \mathrm{df}=1$ ), but little difference was observed in the total number of days absence from training (acute,
1210 days; overuse, 1142 days; $\mathrm{p}=0.20 ; \chi^{2}=2.0 ; \mathrm{df}=$ 1) or sailing (acute, 507 days; overuse, 437 days; $p=0.02$; $\left.\chi^{2}=5.9 ; \mathrm{df}=1\right)$. There was a significantly higher incidence of injury in training (8.6/1000 training hours) than in sailing $(2.2 / 1000$ sailing hours $)\left(\mathrm{p}=0.05 ; \chi^{2}=3.8 ; \mathrm{df}=\right.$ 1).

The greatest proportion of the injuries affected the upper limb which included the shoulder $(40 \%)$, followed by the lower limb $(25 \%)$, the trunk $(20 \%)$, and the head and neck (14\%). Figures 3 and 4 show the anatomical location and pathology of all injuries sustained. The shoulder and upper arm (15\%) (long head of biceps tendinopathy, 38\%; acromioclavicular joint sprains, 19\%) and the lumbar spine (12\%) (facet joint sprains, 37\%; degenerative changes, $26 \%$ ) were the most commonly affected locations. Joint/ligament sprains $(27 \%)$ and tendinopathies $(20 \%)$ were the most common pathologies.

Table 3 displays the most common sailing, training, and non-specific overuse injury diagnoses, and table 4 shows the injuries causing the greatest number of days absence. Preexisting injuries ( $8 \%$ ) caused a disproportionate absence from

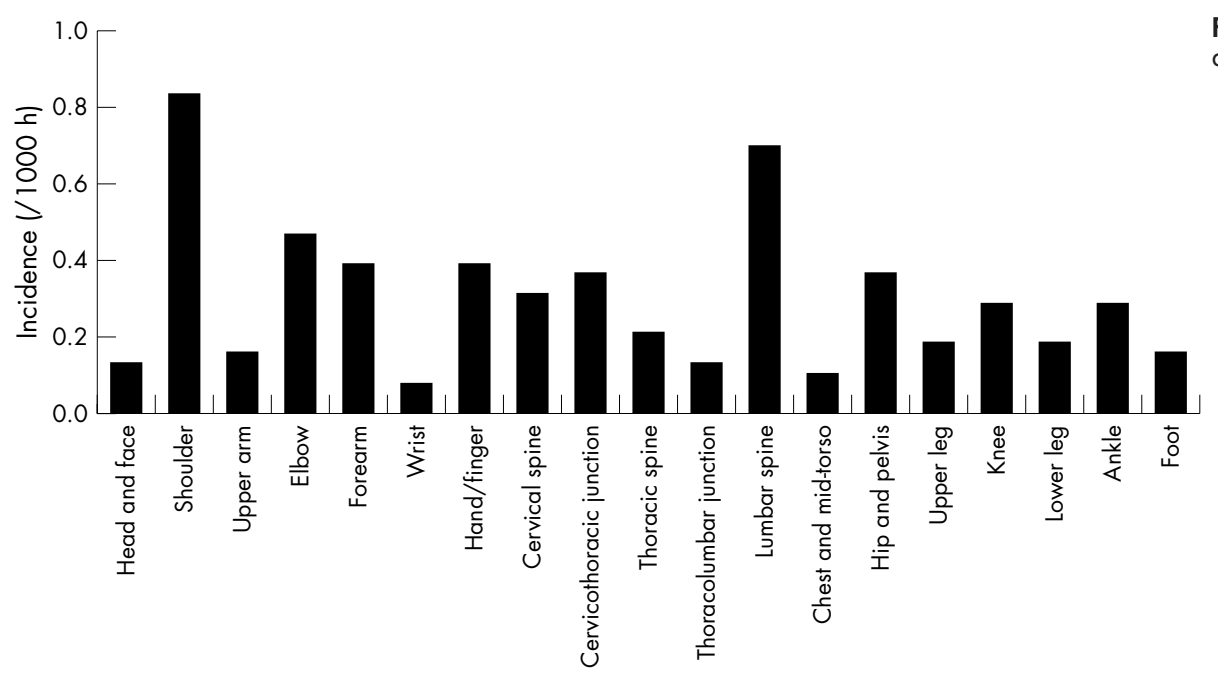

Figure 3 Incidence of injuries by anatomical location. 


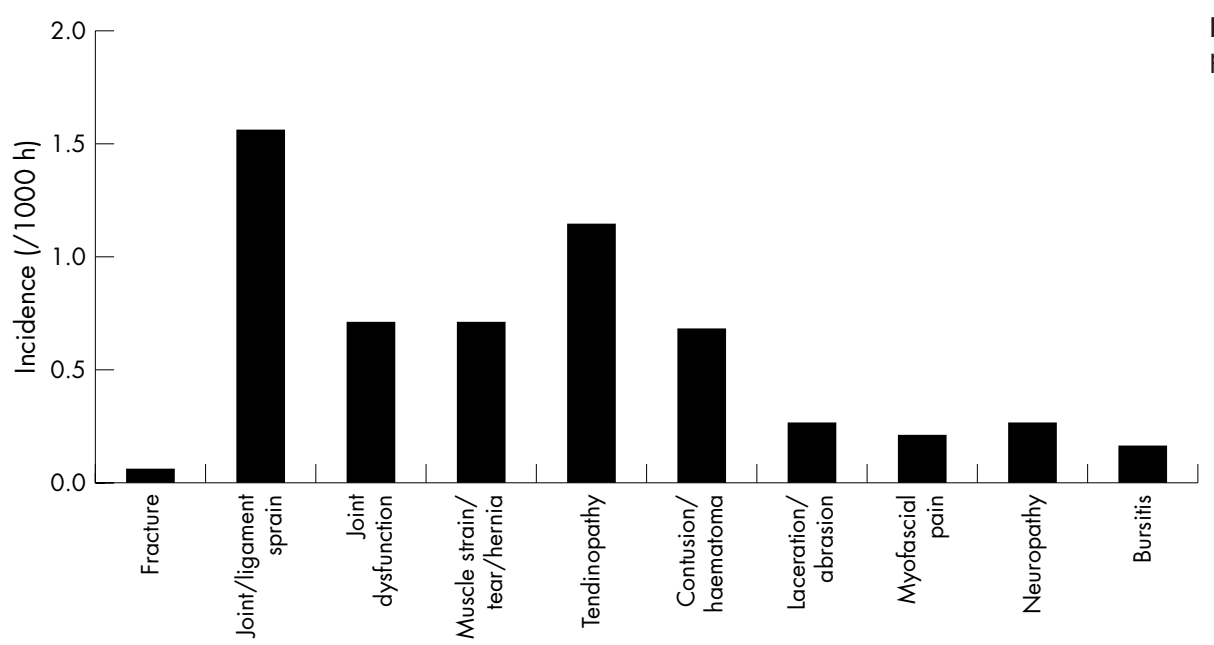

Figure 4 Incidence of injuries by pathology.

sailing (26\%) and modification of training (23\%), whereas recurrent injuries $(11 \%)$ and new injuries $(81 \%)$ showed similar or lower proportions $(8 \%, 12 \%$ and $65 \%, 65 \%$ respectively).

Table 5 shows the incidence of injury and illness of the crew in different positions. Grinders had the highest overall incidence of injuries (7.7/1000 sailing and training hours), and bowmen had the highest incidence of sailing injuries (3.2/1000 sailing hours).

\section{Illnesses}

The incidence $(40 \%)$ of upper respiratory tract infections (URTIs) was significantly higher than that of all other medical conditions $\left(\mathrm{p}<0.0005 ; \chi^{2}=17.3 ; \mathrm{df}=1\right)$ (fig 5). They also caused most days of absence from sailing (61\%) and modification of training (57\%).

\section{DISCUSSION}

This is the first prospective cohort study of America's Cup yacht racing to document and report both the incidence and severity of injuries and illnesses; consequently it is difficult to make comparisons with previous studies. However, the

\begin{tabular}{|c|c|}
\hline Injury & Number \\
\hline \multicolumn{2}{|l|}{ Sailing } \\
\hline Elbow/forearm haematoma & $11(0.4)$ \\
\hline Thoracolumbar junction sprain & $6(0.2)$ \\
\hline Neck muscle strain & $5(0.2)$ \\
\hline Lumbar spine pathology & $5(0.2)$ \\
\hline \multicolumn{2}{|l|}{ Training } \\
\hline Lumbar spine pathology & $7(0.8)$ \\
\hline Lateral ankle sprain & $7(0.8)$ \\
\hline Biceps tendinopathy & $6(0.7)$ \\
\hline Illiotibial band syndrome & $4(0.5)$ \\
\hline \multicolumn{2}{|l|}{ Non-specific overuse } \\
\hline Lateral/medial elbow tendinosis & $8(0.2)$ \\
\hline Biceps tendinopathy & $5(0.1)$ \\
\hline Cervicothoracic junction pathology & $5(0.1)$ \\
\hline Intersection syndrome & $3(0.1)$ \\
\hline \multicolumn{2}{|l|}{ All injuries } \\
\hline Lumbar spine pathology & $17(0.4)$ \\
\hline Cervicothoracic junction pathology & $14(0.4)$ \\
\hline Biceps tendinopathy & $12(0.3)$ \\
\hline Lateral ankle sprain & $10(0.3)$ \\
\hline
\end{tabular}

inclusive injury definition used in this study is similar to that adopted in recent studies in other sports, allowing incidence comparisons to be made. The incidence of injury in this study (5.7 injuries/1000 hours) was considerably lower than in professional sports involving contact and collision, such as rugby league $(114)^{19}$ and soccer $(81),{ }^{20}$ but similar to the incidence reported in non-contact sports such as professional cricket $(7)^{21}$ and amateur ocean yacht racing (1). ${ }^{16}$ Although the incidence of injuries is low in comparison with many other professional sports, the higher volume of sailing and training exposure incurred by America's Cup crews increases the burden of injuries and illnesses on a team. Consequently the prevalence of crew absence from full training $(15.4 \%)$ was similar to the average absence from training and competition in professional rugby union $(23 \%),{ }^{22}{ }^{23}$ in which the volume of training and competition performed was much lower: 324-552 minutes a week ${ }^{1023}$ compared with 720-2050 minutes a week in the current study.

There was a reduction in the average volume of sailing and training exposure over the study periods. The incidence, however, failed to follow the same trend, with the highest incidence of injury occurring during the periods of highest training intensity, indicating that the intensity of the training exposure, rather than the volume, may be a more important injury risk factor. Similar findings have been reported in semiprofessional rugby league. ${ }^{9}$ The incidence of injury in the America's Cup racing period (period D) was lower than the incidence in the other study periods. This contrasts with observations from professional soccer ${ }^{24}$ and professional rugby union, ${ }^{22} 23$ in which a significantly higher incidence of injury has been reported during competition than out of competition. A decrease in the training intensity during the racing period and a reluctance of the crew to indicate any injuries for fear of jeopardising their position on the race boat are the most likely reasons. Furthermore, the incidence of injury in training was significantly higher (8.6) than the incidence of injury in sailing (2.2). This is probably a result of the higher intensity of the training performed compared with the sailing, as well as many of the crew not having performed any regular formal training programmes before joining the America's Cup. It should also be noted that strength and conditioning is a recent addition to sailing and is generally not performed outside of the professional sailing environment. However, the high volume of sailing performed $(78 \%$ of total time), resulted in sailing (30\%) sustaining a similar proportion of injuries to training (34\%). 


\begin{tabular}{|c|c|c|c|}
\hline Injury & $\begin{array}{l}\text { Days absent } \\
\text { from sailing }\end{array}$ & Injury & $\begin{array}{l}\text { Days absent } \\
\text { from full } \\
\text { training }\end{array}$ \\
\hline \multicolumn{4}{|l|}{ Sailing } \\
\hline Triceps tendon tear & $35(35)$ & PINE & $70(23)$ \\
\hline Intersection syndrome & $21(21)$ & Intersection syndrome & $66(66)$ \\
\hline Hand/finger laceration & $12(3)$ & Finger sprain & $51(26)$ \\
\hline PINE & $8(3)$ & Triceps tendon tear & $35(35)$ \\
\hline \multicolumn{4}{|l|}{ Training } \\
\hline Navicular fracture & $102(102)$ & Lumbar spine pathology & $98(14)$ \\
\hline SLAP lesion & $93(93)$ & SLAP lesion & 93 (93) \\
\hline Olecranon fracture & $55(55)$ & Rotator cuff injury & $92(46)$ \\
\hline Lumbar spine pathology & $47(7)$ & Lateral ankle sprain & $55(8)$ \\
\hline \multicolumn{4}{|l|}{ Non-specific overuse } \\
\hline Cervical spine degeneration & $196(196)$ & Cervical spine degeneration & $198(198)$ \\
\hline Inguinal hernia & $90(45)$ & Biceps tendinopathy & $133(27)$ \\
\hline PINE & $57(29)$ & PINE & $123(62)$ \\
\hline Intersection syndrome & 37 (12) & Inguinal hernia & $118(59)$ \\
\hline \multicolumn{4}{|l|}{ All } \\
\hline Cervical spine degeneration & $196(98)$ & Cervical spine degeneration & $227(114)$ \\
\hline Navicular fracture & 102 (102) & PINE & 224 (37) \\
\hline SLAP lesion & $93(93)$ & Biceps tendinopathy & $171(14)$ \\
\hline Inguinal hernia & $90(30)$ & Lumbar spine pathology & $168(10)$ \\
\hline
\end{tabular}

The most common sailing injuries were contusions and sprains, occurring predominantly as a result of impact with boat hardware-for example, spinnaker poles, winch handles, foot chocks, ropes, sails, and winches. These results suggest that the ergonomic design and placement of deck hardware on America's Cup racing yachts should consider the optimum movement patterns and safety of the crew. ${ }^{7}$ Training injuries were largely sprains, tendinopathies, and muscle strains, most of which were sustained during weight training. Activities involving shoulder abduction and external rotation, particularly when lifting near maximal loads, such as on the shoulder press and bench press, may compromise the stability of the shoulder and increase the risk of a shoulder injury, ${ }^{25}$ and may explain the high proportion of weight training related shoulder injuries (38\%). The most severe training injuries resulted from fitness testing, which is in accordance with professional rugby union and may question the appropriateness of maximal testing with elite athletes. ${ }^{1023}$ Although the benefits of maximal intensity testing are widely acknowledged, testing protocols should avoid placing athletes at an unnecessary risk of injury.

The greater proportion of acute injuries $(67 \%)$ in this study was in contrast with the findings of Allen, ${ }^{4}$ who reported a majority of overuse injuries (68\%) in a study of an all female America's Cup crew. This may be a consequence of differences in the diagnosis or definition of acute versus overuse injuries and/or an increased risk of acute injury in this study. The severity of the overuse injuries, which were predominantly tendinopathies (38\%), was significantly greater than the severity of acute injuries, possibly because of the demands of high repetition activities, ${ }^{26}$ such as grinding, top handle winching, sail trimming, and steering.

Many America's Cup athletes also participate in off-shore yacht races, such as the Volvo Ocean Race. However, the demands placed on the athletes are very different, and this is reflected in the injury epidemiology. In professional ocean yacht racing, a large proportion of injuries (33\%) occur below the deck because of the greater volume of time spent below deck and the violent and sudden movements of the yachts, ${ }^{17}$ whereas in the current study, most injuries during sailing resulted from impact with boat hardware on, or above, the deck. Furthermore, helmsmen were at a greater risk of overuse injuries during ocean racing, because of the arduous demands of steering in heavy weather conditions. Further differences between America's Cup sailing and other sailing disciplines can be seen in amateur ocean yacht racing (the BT Global Challenge), in which a larger proportion of the incidents are illness related conditions (56\%), ${ }^{16}$ compared with this study (35\%), and in small boat sailing and board sailing, in which most injuries are to the knee and lumbar spine, resulting from extensive forces applied during the sustained position of "hiking", ${ }^{27}$ an activity that is uncommon in America's Cup sailing.

Upper limb and shoulder injuries, most commonly tendinopathies and neuropathies involving the long head of biceps tendon, elbow flexor/extensor tendinosis, and

\begin{tabular}{|c|c|c|c|c|c|c|}
\hline \multirow[b]{2}{*}{ Crew position } & \multirow[b]{2}{*}{ Number } & \multicolumn{3}{|l|}{ Injury } & \multirow[b]{2}{*}{ Illness } & \multirow{2}{*}{$\begin{array}{l}\text { All } \\
\text { incidents }\end{array}$} \\
\hline & & Sailing & Training & All & & \\
\hline Grinder & 12 & $33(3.1)$ & 33 (11.2) & $101(7.7)$ & $51(3.9)$ & 152 (11.5) \\
\hline Pitman & 3 & $5(2.0)$ & $9(12.2)$ & 24 (7.3) & $10(3.0)$ & $34(10.3)$ \\
\hline Utility & 4 & $5(1.5)$ & $12(12.2)$ & $28(6.4)$ & $16(3.6)$ & $44(10.0)$ \\
\hline Bowman & 4 & $11(3.2)$ & $1(1.0)$ & $22(5.0)$ & $11(2.5)$ & $33(7.5)$ \\
\hline Navigator & 2 & $1(0.6)$ & $4(8.1)$ & $6(2.7)$ & $8(3.6)$ & $14(6.4)$ \\
\hline Trimmer & 7 & $10(1.7)$ & $13(7.6)$ & $33(4.3)$ & $19(2.5)$ & $52(6.8)$ \\
\hline Helmsman & 3 & $1(0.4)$ & $2(2.7)$ & $6(1.8)$ & $4(1.2)$ & $10(3.0)$ \\
\hline All & 35 & $66(2.2)$ & $74(8.6)$ & $220(5.7)$ & $119(3.1)$ & $339(8.8)$ \\
\hline
\end{tabular}

Values are number with incidence/ 1000 hours in parentheses. 


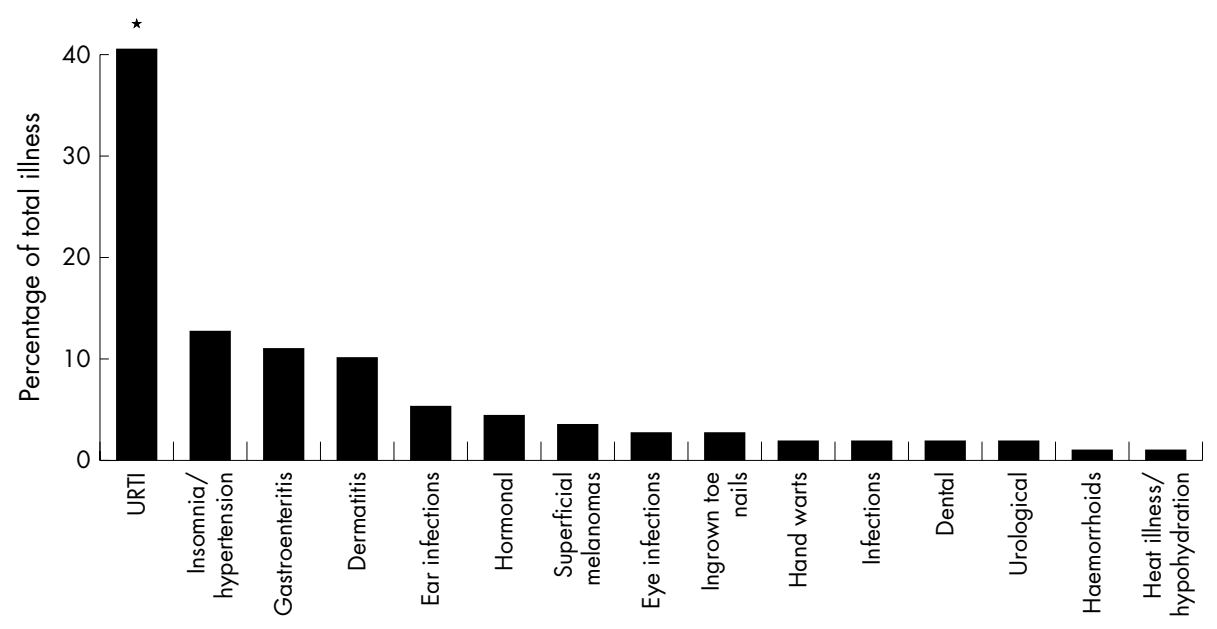

Figure 5 The proportion of illnesses by diagnosis. ${ }^{*}$ Significantly higher incidence than all other illnesses $\left(p<0.0005 ; \chi^{2}=17.3 ; d f=1\right)$.

entrapment of the posterior interosseous nerve (PINE), accounted for the largest proportion of the injuries reported $(40 \%)$. This finding is probably due to the intensive demands placed on the upper limb during most sailing and training activities, and is consistent with that reported previously. ${ }^{4} 12$ Although PINE has not been reported in previous sailing studies, the signs and symptoms seem similar to those reported as "grinder's elbow" in an early America's Cup study by Miller. ${ }^{12}$ Miller referred to this condition as: "a frequently occurring overuse disorder characterised by a combination of tendinitis, fasciitis and epicondylitis causing local tenderness near the elbow and forearm". However, further studies are required to confirm the risk of PINE in sailing.

Common lumbar spine injuries included lumbar spine facet joint sprains and thoracolumbar junction sprains, thought to be primarily a result of the forward flexed and rotated position of the spine during the activities of grinding, pulling ropes, and trimming sails. ${ }^{7}$ The repetitive nature of these tasks may increase the associated risk. ${ }^{29}$ Similar injuries have been often reported in other sports such as rowing ${ }^{30}$ and kayaking, ${ }^{31}$ in which repetitive actions involving the lumbar spine are also common. Injuries to the cervical spine included cervicothoracic sprains and dysfunctions. Many of these may have been related to the sustained posture of cervical spine protraction and extension, characteristic of trimmers while looking up at sails and helmsmen while steering. ${ }^{4}$ Although there is no conclusive evidence to suggest that degenerative joint changes may be attributed to sailing, the high incidence of these injuries in this population may indicate that the sustained postures and high repetition activities particular to America's Cup sailing may contribute to this degeneration over time.

Owing to the high strength and power requirements of the grinders, it is not surprising that they had the greatest overall risk of sustaining an injury, predominantly in the upper limbs and shoulders. During sailing, however, the bowmen had the highest incidence of injury, which may be attributed to the high intensity of the activities occurring within the very small and unstable area of the bow (the narrow front section of the boat). ${ }^{7}$ Helmsmen, on the other hand, are the "drivers" of the boat, a role that is predominantly cognitive and less physically demanding; consequently, they were at the lowest risk of sustaining an injury.

Although pre-existing injuries accounted for a relatively small percentage of all injuries $(8 \%)$, they were, on average, of greater severity than both new and recurrent injuries.
These results suggest the importance of thorough medical screening before the start of a season or campaign and highlight the risks associated with contracting athletes with pre-existing conditions.

We report in this study that cervical spine degeneration, PINE, long head of biceps tendinopathy, and lumbar spine pathologies caused the greatest absence from sailing and training. Consequently injury prevention, treatment, and rehabilitation plans for these injuries should be prioritised.

Illnesses made up 35\% of all reported incidents, and URTIs accounted for most illness related conditions (40\%) followed by stress related disorders-for example, hypertension and insomnia (13\%). URTIs also accounted for most illness related days absent from sailing (61\%) and training (57\%). The high incidence of URTIs may be attributed to the stresses associated with the America's Cup-for example, living in hotels away from home for long periods of time, intense training and sailing demands, long working days (with most days in excess of 12 hours), little recovery time or "time off", cold and wet weather conditions, and routine monotony, all of which could increase stress and contribute to suppressed immune system function and increased risk of URTIs. ${ }^{32}$ Nutritional strategies, such as maintaining a positive energy balance, consuming a well balanced diet high in carbohydrate, protein, and micronutrients, and the intake of carbohydrate before, during, and after training, ${ }^{33}$ as well as regular monitoring of markers of fatigue and overtraining are reported to help prevent or minimise the risk of immunosuppression and subsequent URTIs. ${ }^{34}$

This study only reported medically treated injuries as a result of scheduled sailing and training, and therefore it is acknowledged that there may have been minor injuries that could have been precursors to more chronic injuries that were not recorded. Furthermore, injuries occurring as a result of boat maintenance and shore work, which account for a considerable proportion of an America's Cup athlete's total

\section{What is already known on this topic}

- The America's Cup is a professional and physically demanding intermittent team sport with very little known of the risk of injury and illness

- Injury incidence and severity data have not been reported previously 


\section{What this study adds}

- The detailed analysis of injury incidences and severity shows that America's Cup athletes are at risk of illness and injuries, which are a function of the role and the activity performed

- There is a need for comprehensive support in managing the health and fitness of America's Cup athletes

daily exposure, were not accounted for, and therefore the results may have under-reported the total risk. The America's Cup is also unique in that an injured athlete can often still sail by either modifying their role or changing their position on-board the yacht. Future studies may benefit from monitoring any such changes in the crew.

This study highlights that, because of the high sailing and training demands, America's Cup crew members are at risk of injury and illness, as evident by the prevalence of crew absent from sailing $(6.2 \%)$ and training $(15.4 \%)$. However, in comparison with many other professional intermittent team sports, very few resources are allocated to the health and fitness of America's Cup athletes, with the emphasis focusing largely on the research and development of the boats and hardware. ${ }^{7}$ As such large volumes of sailing and training are performed, sports science and medicine is usually reactive rather than proactive, and the rest and recovery of the athletes are often taken for granted. The results of this study highlight the need for effective sports science and sports medicine in the America's Cup. To reduce the risk associated with injury and illness, appropriate attention should be placed on the health of the athletes, including regular health and medical assessments, comprehensive medical treatment, physiotherapy (prehabilitation and rehabilitation), preventive strength and conditioning programmes, nutrition and hydration strategies, as well as the monitoring of total work loads in order to manage and implement appropriate recovery strategies. Furthermore, particular significance should be placed on the more severe incidents with respect to the allocation of preventive and therapeutic resources. Further studies investigating the potential risks of injury and illness are required to better understand the aetiology of America's Cup yacht racing injuries.

\section{ACKNOWLEDGEMENTS}

We acknowledge Mr Romolo Ranieri, for the collection of sailing data, and Dr Liz Sewell and Dr Iain Wood for their input in the reporting of injuries and illnesses.

\section{Authors' affiliations}

V J Neville, School of Sport and Exercise Science, Loughborough University, Loughborough, UK

J Molloy, Auckland University of Technology, Auckland, New Zealand J H M Brooks, University of Leicester, Leicester, UK

D B Speedy, Department of General Practice and Primary Care,

University of Auckland, Auckland

G Atkinson, Research Institute for Sport and Exercise Sciences, Liverpool John Moores University, Liverpool, UK

Competing interests: none declared

\section{REFERENCES}

1 Blondelle P, Simmonet J. A physical therapist at the America's Cup 1983. (In French) Union Med Can 1984;113:637-9.

2 Bertrand J. Never give in. Sail (Boston) Sep 1985;19:56-60.

3 Bauer S. Coming about: can a bunch of guys with names like Rambo, Darling and Adam-12 bring back the America's Cup? They're working on it. Ultrasport (Boston, Mass) Jul 1986;3:44-51

4 Allen JB. Sports medicine and sailing. Phys Med Rehabil Clin N Am 1999; 10:49-65.
5 Lambert Y, Lelguen C. Medical controls and preparation of the French team for the America's Cup (1999-2000). (In French) Science and Sports 2001;16:95-9.

6 Bessinger T. Men at work. Sailing World (Newport RI) Nov 2002;41:94-8.

7 Allen JB, Dent D, Fagan K. Sports medicine injuries in the America's Cup 2000. New Zealand Journal of Sports Medicine. 2005: in press.

8 Jones BH, Cowan DN, Tomlinson JP, et al. Epidemiology of injuries associated with physical training among young men in the army. Med Sci Sports Exerc 1993;25:197-203.

9 Gabbett TJ. Influence of training and match intensity on injuries in rugby league. J Sports Sci 2004;22:409-17.

10 Brooks JHM, Fuller CW, Kemp SPT, et al. A prospective study of injuries and training amongst the England 2003 Rugby World Cup squad. Br J Sports Med 2005:39:288-93.

11 Fuller CW, Drawer S. The application of risk assessment in sport. Sports Med 2004;34:349-56.

12 Miller C. Treating the America's Cup sailors. Phys Sportsmed 1987; 15:172-8.

13 Bugge $M$. The third Whitbread Round the World Race. Injury 1986; 17:196-8.

14 Nilson R. Medical support on-board the worlds toughest yacht race. (In Swedish) Nord Med 1994;109:28-31.

15 Branth S, Hambraeus L, Westerterp K, et al. Energy turnover in a sailing crew during offshore racing around the world. Med Sci Sport Exerc 1996;28:1272-6.

16 Price CJS, Spalding TJW, McKenzie C. Patterns of illness and injury encountered in amateur ocean yacht racing: an analysis of the British Telecom Round the World Yacht Race 1996-1997. Br J Sports Med 2002;36:457-62.

17 Spalding T, Malinen T, Tomson M. Analysis of medical problems during the 2001-2002 Volvo Ocean Race. New Zealand Journal of Sports Medicine. 2005: in press.

18 Jackson AS, Pollock ML. Generalised equasions for predicting body density of men. Br J Nutr 2004;91:161-8.

19 Stephenson S, Gissane C, Jennings D. Injury in rugby league: a four year prospective survey. Br J Sports Med 1996;30:331-4.

20 Junge A, Dvorak J, Graf-Baumann T. Football injuries during the world cup 2002. Am J Sports Med 2004;32S23-7. (suppl 1).

21 Leary T, White JA. Acute injury incidence in professional county club cricket players (1985-1995). Br J Sports Med 2000;34:145-7.

22 Brooks JHM, Fuller CW, Kemp SPT, et al. Epidemiology of injuries in English professional rugby union: part 1: match injuries. Br J Sports Med 2005;39:757-66.

23 Brooks JHM, Fuller CW, Kemp SPT, et al. Epidemiology of injuries in English professional rugby union: part 2: training injuries. $\mathrm{Br} J$ Sports Med 2005;39:767-75.

24 Hägglund $M$, Waldén $M$, Ekstrand J. Exposure and injury risk in Swedish elite football: a comparison between seasons 1982 and 2001. Scand J Med Sci Sports 2003;13:364-70.

25 Fees M, Decker T, Snyder-Mackler L, et al. Upper extremity weight-training modifications for the injured athlete: a clinical perspective. Am J Sports Med 1998;26:732-42.

26 Murrell GA. Understanding tendinopathies. Br J Sports Med 2002:36:392-3

27 Rieckert H. Sports medicine aspects of sailing and windsurfing. (In German) Deutsche Zeit Sportmed 1993;44:301-3.

28 Shephard RJ. Biology and medicine of sailing: an update. Sports Med 1997;23:350-6.

29 Bono CM. Low-back pain in athletes. J Bone Joint Surg [Am] 2004;86:382-96.

30 McGregor AH, Anderton L, Gedroyc WMW. The trunk muscles of elite oarsmen. Br J Sports Med 2002;36:214-16.

31 Fiore DC, Houston JD. Injuries in whitewater kayaking. Br J Sports Med $2001 ; 35: 235-41$

32 Nieman DC. Is infection risk linked to exercise workload? Med Sci Sports Exerc 2000;32(suppl 7):S406-11.

33 Gleeson M, Lancaster GI, Bishop NC. Nutritional strategies to minimise exercise-induced immunosuppression in athletes. Can J Appl Physiol $2001 ; 26$ (suppl):S23-35.

34 Gleeson M. Biomechanical and immunological markers of over-training J Sports Sci Med 2002;1:31-41.

\section{COMMENTARY}

This is an excellent paper full of very detailed analysis concerning the injuries sustained during the high intensity event which is Americas Cup Yacht Racing. It is extremely hard to collect accurate data for such an event, and the authors should be congratulated on their methodology and analysis. The results presented serve as an extremely valuable baseline to allow further work to be undertaken on reducing injuries and improving equipment and training.

The Warwickshire Nuffield Hospital, Leamington Spa, Warwickshire UK; tim@timspalding.com 


\section{COMMENTARY}

The America's Cup is the premiere event in one of the oldest sports known world wide, yet the documented knowledge on sports medicine and sports science in sailing has only recently begun to grow. Although there are millions of dollars spent on boats, sails, equipment, weather data collection, rules, and strategy, very little value or emphasis has been placed on the human performance factor and the care of the sailor athletes. This article successfully documents the epidemiology of injuries and illnesses that may occur on an America's Cup team during the racing season, including the types, locations, and mechanisms of injury. It correlates well with previous similar studies, and also comments on injury incidence, severity, and days absent from the sport. Further studies should investigate the financial long term costs of these injuries and the risk profile of teams with inadequate healthcare programmes, preventive and therapeutic measures, and ergonomic design considerations. Hopefully future America's Cup teams will consider this study and the growing body of literature that indicates the definite need for the support and care of sailor athletes by an appropriately funded team of sports medicine and sports science professionals.

J B Allen

SailSportMed Inc, Wilmington, North Carolina, USA; Aasail@aol.com

\section{ELECTRONIC PAGES}

\section{Online case reports}

T he following electronic only articles are published in conjunction with this issue of BJSM (See also page 366)

An unusual case of facial nerve palsy following soccer related minor head injury

\section{E F Leitch, J R Hanson}

A 16 year old amateur soccer player sustained a minor head injury while contesting a ball in the air. He was unconscious for two minutes and remained "dizzy" for about an hour. After two days he developed a profound left lower motor neurone facial nerve palsy. He was found to have a complex fracture of the left petrous temporal bone, with fluid in the left middle ear and left mastoid. Treatment was conservative with oral steroids and oral co-amoxiclav and a left myringotomy to decompress his middle ear. The spectrum of aetiology, presentation, and prognosis for facial nerve injuries is discussed.

(Br J Sports Med 2006;40:e9) http://bjsm.bmjjournals.com/ cgi/content/full/40/4/e9
Carotid artery dissection after treadmill running D J M Macdonald, E C A McKillop

The case is presented of carotid artery dissection causing Horner's syndrome in a 25 year old woman after treadmill running. She presented with characteristic eye signs and mild pain. Early diagnosis and treatment was associated with no long term, serious complications. It is now recognised that carotid artery dissection is more common than previously thought. Better imaging of the carotid artery has facilitated the diagnosis, and it is now essential to rule out this potentially fatal condition in patients presenting with postganglionic Horner's syndrome. It is accepted that relatively trivial trauma can cause a carotid artery dissection, and many sporting activities may place young, fit, healthy people at risk.

(Br J Sports Med 2006;40:el0) http://bjsm.bmjjournals.com/ cgi/content/full/40/4/e10 